\title{
THE SAMOTHRACE EARTHQUAKE OF MAY 2014 AND THE DISPLACEMENTS ESTIMATIONS USING PERMANENT GPS STATIONS DATA
}

\author{
Bitharis S. ${ }^{1}$, Fotiou A. ${ }^{1}$, Pikridas C. ${ }^{1}$, Rossikopoulos D. ${ }^{1}$, Pavlides S. ${ }^{2}$ and \\ Chatzipetros A. ${ }^{2}$ \\ ${ }^{1}$ Aristotle University of Thessaloniki, Department of Geodesy and Surveying, 54124, Thessaloniki, \\ Greece,stylbith@gmail.com,afotiou@topo.auth.gr, cpik@topo.auth.gr,rossi@topo.auth.gr \\ ${ }^{2}$ Aristotle University of Thessaloniki, Department of Geology, 54124, Thessaloniki, Greece, \\ pavlides@geo.auth.gr,ac@geo.auth.gr
}

\begin{abstract}
The contribution of GPS networks in monitoring seismic events is important because they can provide a direct geometrical information on the Earth's crust using satellite observations In this study position displacements of permanent GPS stations are determined due to intense seismic events in the North Aegean area after the strong earthquake on May 24, 2014. The horizontal coseismic displacements for the Samothrace Island were estimated at $9.4 \mathrm{~cm}$ and for Lemnos Island at $5.2 \mathrm{~cm}$ respectively. A study period of seven days was enough to show that the deformation evolved into two days.
\end{abstract}

Keywords: North Aegean, earthquake monitoring, coseismic displacements.

\section{Пврі́ $\eta \psi \eta$}

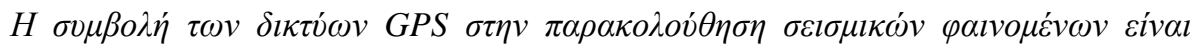

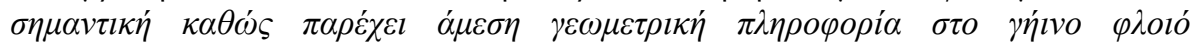

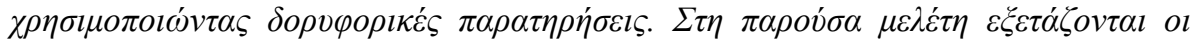

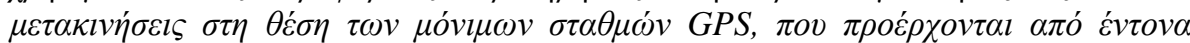

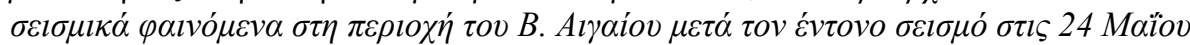

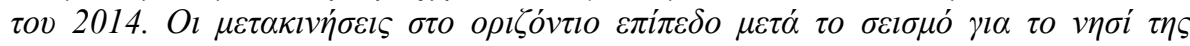
$\Sigma \alpha \mu о \theta \rho \alpha ́ \kappa \eta \varsigma ~ \varepsilon \kappa \tau l \mu \eta ́ \theta \eta \kappa \alpha v ~ \sigma \varepsilon 9.4 \mathrm{~cm} \mathrm{\kappa \alpha l} \mathrm{\gamma l \alpha} \mathrm{\tau o} \mathrm{v \eta \sigma i} \mathrm{\tau \eta \varsigma} \mathrm{\Lambda \eta ́ \mu vov} \sigma \varepsilon 5.2 \mathrm{~cm} \alpha v \tau \imath \sigma \tau o i ́ \chi \omega \varsigma$.

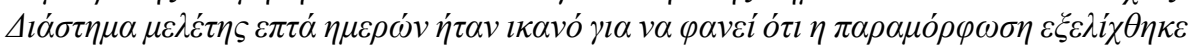

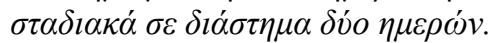

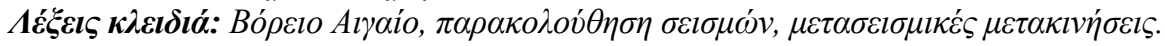

\section{Introduction}

On May 24, 2014 at 09:25 UTC a strong earthquake (EQ) of Mw6.8 occurred with epicentre between Samothrace and Limnos islands and a focal depth of $14 \mathrm{~km}$. This research focused on the estimation of crustal earth displacements at the northeast Aegean Sea using GPS observations for a few days period, before and after the seismic event. The contribution of GNSS permanent networks is very important because these networks can provide continuous and accurate satellite observations, giving the opportunity to monitor the sites location and their temporal variation as well. Except the ability to accurately detect tiny ground movements they can offer near-real time evidence of slow slip activity that seismometers do not necessarily capture. The used GNSS network of 21 permanent 
stations, where 9 of them belongs to the IGS (International GNSS Service) network, 3 to the EPN (Euref Permanent Network), 6 to the SmartNet Greece (http://www.metricanet.gr), 2 to the NOANet (Ganas et al., 2011) and 1 of them to the HEPOS network (http://www.hepos.gr/). The GNSS network with the focal mechanism of Samothrace EQ are illustrated in Figure 1.

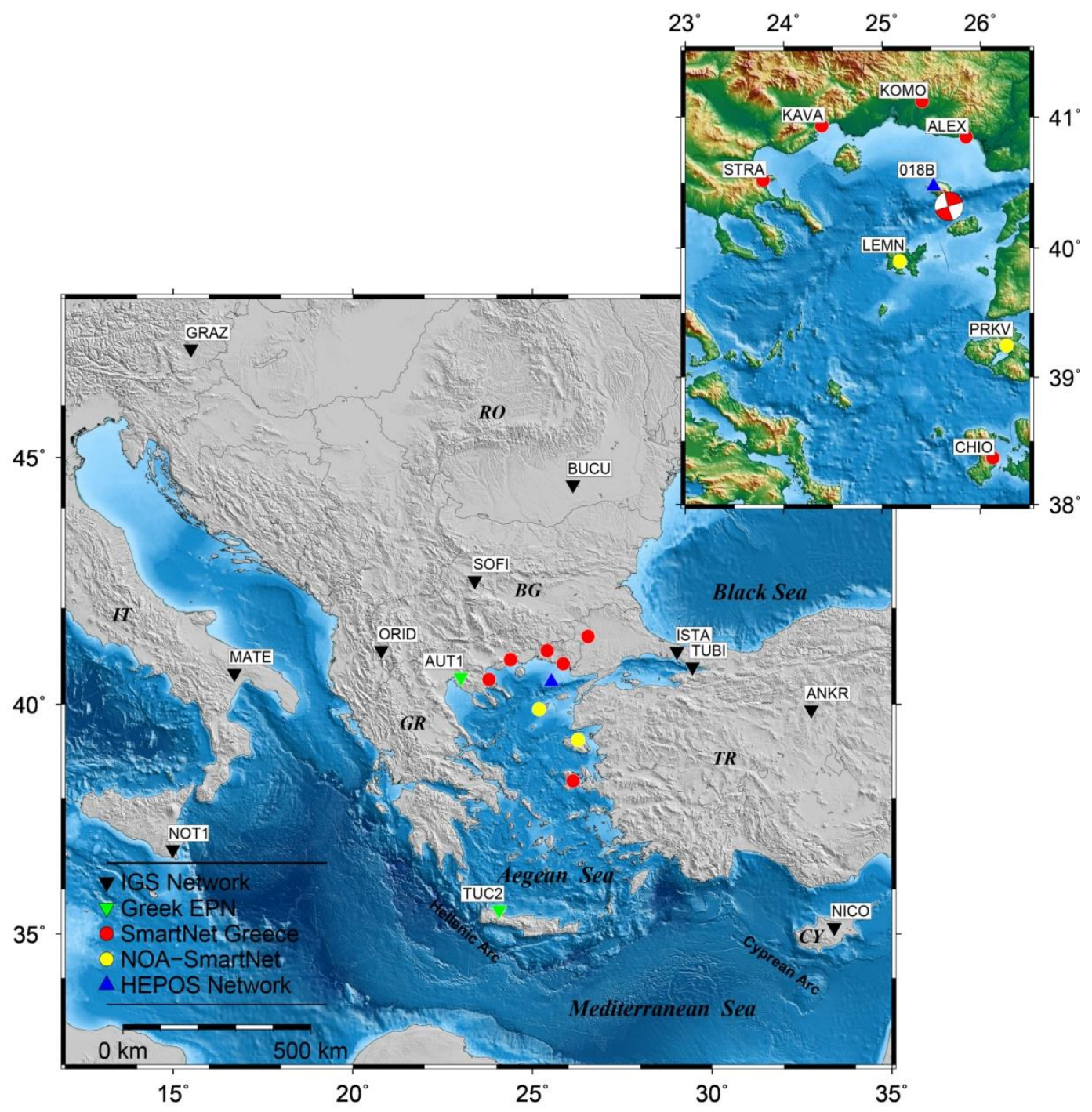

Figure 1 - The GNSS network of permanent stations and the focal mechanism of the Samothrace earthquake on May 24, 2014.

The focal mechanism is a product from the Global Centroid Moment Tensor (GCMT) project based on the methodology given by Dziewonski et al. (1981).

\section{Process of GPS data}

The satellite geodetic methods such as GPS are valuable for the analysis and estimations of displacements due to earthquake events. In order to study the influence of May 24, 2014 EQ on site displacements a time period of seven days was selected, from May 20, 2014 to May 26, 2014. Specifically data for four days before and three days after the event were processed. Data analysis was based on $30-$ sec daily GPS observations and elevation cut-off angle $10^{\circ}$. The process was held 
on the current reference frame ITRF2008 (Altamimi et al., 2011) using the scientific package GAMIT/GLOBK (Herring et al., 2010). Firstly the phase code data were processed in order to estimate the 3-D relative positions of ground stations. IGS final orbits were used and atmospheric zenith delays estimated every two hours interval by means of the VMF1 mapping function (Boehm et al., 2006) based on numerical weather models. Phase ambiguity resolution is very important for high precision geodetic applications. In the present work the resolved ambiguities were at the level of $92 \%$ for the narrow lane linear combination, a good enough percentage for our study (e.g., Fotiou and Pikridas, 2012). The reference frame for the daily solutions was defined by fixing seven IGS sites (GRAZ, BUCU, SOFI, ORID, MATE, NOT1, NICO) selected far from the EQ epicentre remaining unaffected by the seismic event. In the remaining stations of the surrounding study area we investigated the effect of EQ on the daily site coordinates.

\section{Results}

The results analysis is basically focused on daily time series coordinate estimations and on the total displacement from the first up to the last day of GPS data process.

\subsection{Time series daily displacements}

The position time series is a very useful tool to monitor the daily variation of site coordinates. A strong EQ have an effect on the time series analysis causing some discontinuities as offsets, which may lead to an unrealistic estimation of geodetic velocities (Bitharis et al., 2015). More generally (Tregoning et al., 2013) showed that large EQs can induce linear velocity errors of up to $0.4 \mathrm{~mm} / \mathrm{yr}$ at sites over $1000 \mathrm{~km}$ from the earthquake locations. In Figure 2, daily displacements expressed in the topocentric (North, East, Up) system are presented for 018B (Samothrace Island) and LEMN (Lemnos Island) stations, which are the two nearest to the EQ epicentre. At these stations the displacements are more intense compared with the other surrounding stations. In addition the station ALEX at Alexandroupolis, in a longer distance from the epicentre, has also a notable but smaller displacement than the two nearest stations.

The estimated displacements from the GNSS time series analysis for Samothrace and Lemnos sites show a reverse motion as expected from the nature and location of the causative fault (Sboras et al., 2015). Moreover the vertical offset is smoother than the horizontal one as happens in a strike-slip fault. The deformation evolved in two days as it is illustrated in Figure 2, where with respect to the North and East components the daily coordinate variations are evident. Concerning the vertical component $(\mathrm{Up})$ is not shown any remarkable variation.

A more clear view is presented in Figure 3 where the differences of the 2-D position between successive days have been accounted for the above three most affected sites. In more detail the horizontal position difference for station 018B at Samothrace Island is $4.76 \mathrm{~cm}$ between the day of seismic event and the previous day. As far the stations at Lemnos and Alexandroupolis the displacements are determined to $2.74 \mathrm{~cm}$ and $1.29 \mathrm{~cm}$ respectively.

It is remarkable in Figure 3 that the direction and the magnitude of the displacements are almost equal for the two pairs of successive days, i.e. between (May 24-23, May 25-24), where the phenomenon has evolved. According to the results the last time span of May 25 to May 26 any additional deformation is not noticed as the relative position difference is smaller than $0.2 \mathrm{~cm}$. A data analysis of a longer time span would give a better insight of post seismic relaxation. 

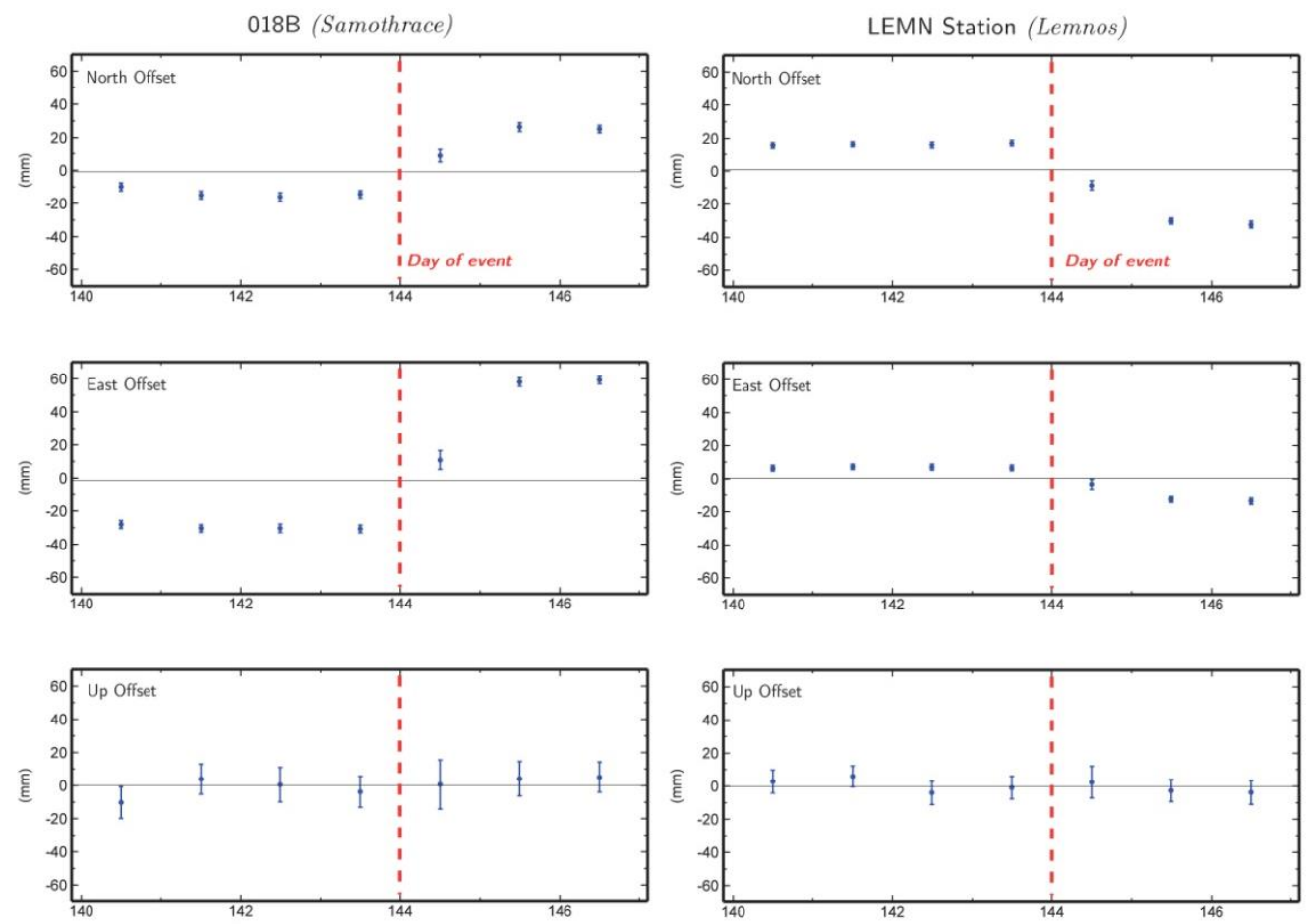

Figure 2 - Time-series position for 018B (left) and LEMN (right) stations from May 20 to May 26, 2014 with respect to the (North, East, Up) topocentric system.

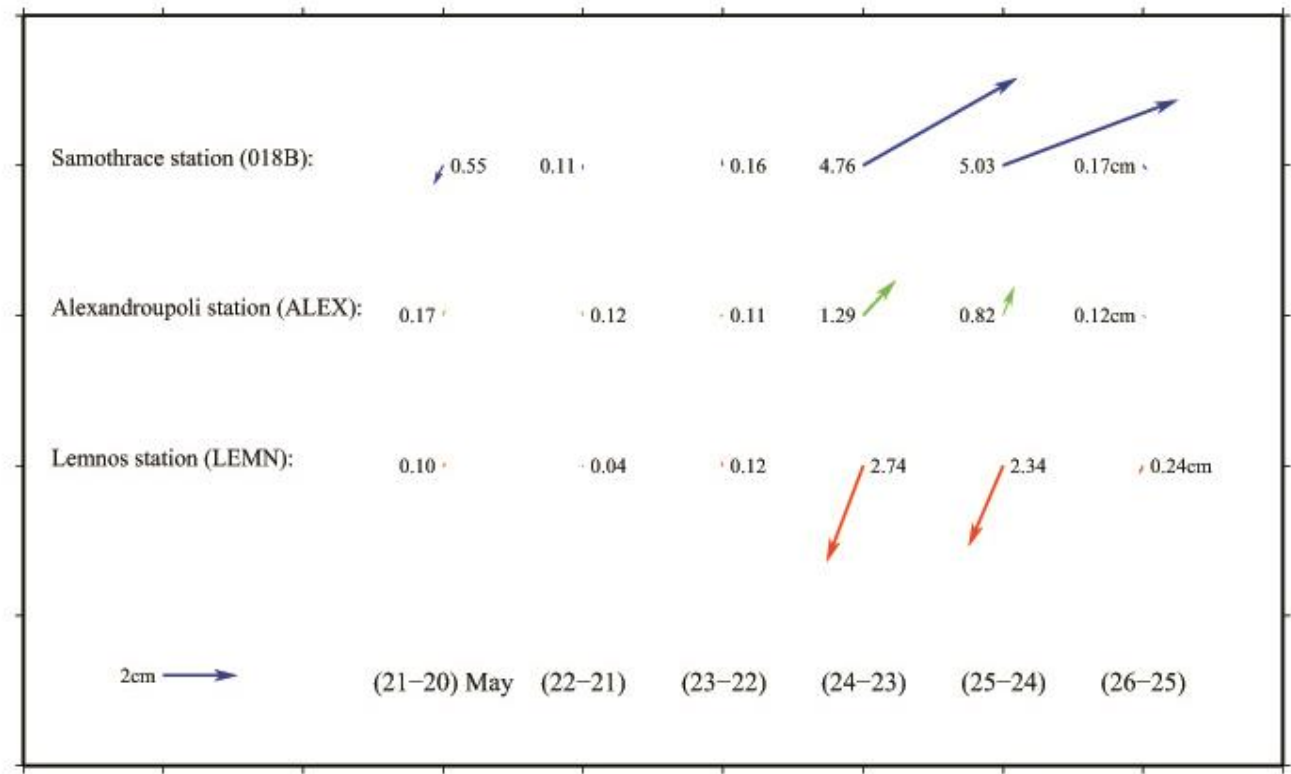

Figure 3 - Daily 2-D displacements for the three nearest to the EQ epicentre GNSS stations.

\subsection{Total seismic displacements}

In order to estimate the 2-D displacement field due the strong Samothrace EQ, we have taken the position difference between the first and the last day (May 20 to May 26) including some days before 
and after the seismic event. As it is shown in Figure 4 and Table 1, the direction of 018B station displacement is ENE (East-Northeast) while its displacement is $9.4 \mathrm{~cm}$. For the LEMN station the direction of its displacement is SSW (South - Southwest) with a magnitude of $5.2 \mathrm{~cm}$. As far the Alex station the corresponding direction is NNE approaching that of 018B (Samothrace) with a magnitude of $2.2 \mathrm{~cm}$. The determined directions of the displacement vectors are compatible to the focal mechanism given by Dziewonski et al. (1981), Sboras et al. (2015).

The tectonic setting of the affected areas consists of the eastern segment of the North Aegean Trough (NAT), which is the extension of the northern splay of the North Anatolian Fault (NAF) in the Aegean. It forms an elongated dextral transtensional basin which is frequently associated with moderate to large earthquakes (see Chatzipetros et al., 2013 and Sboras et al., subm., and references therein). Among others, the seismic history of the broader area that can be directly or indirectly associated to NAT includes strong events such as the ones of 1905 (M 7.3), 1912 (M 7.4), 1982 (M 6.6) and 1983 (M 6.8), although several older large earthquakes are reported in written sources (June 1, 1366; November 12, 1456; 1471; August 12, 1564; April 12, 1572; June 28, 1585; December 5, 1776; July 23, 1719; February 3, 1779; August 6, 1860). The epicentres and exact seismotectonic parameters of those events is however uncertain and in many cases problematic (Papazachos and Papazachou, 1997, 2003; Ambraseys, 2009; Guidoboni and Comastri, 2005).

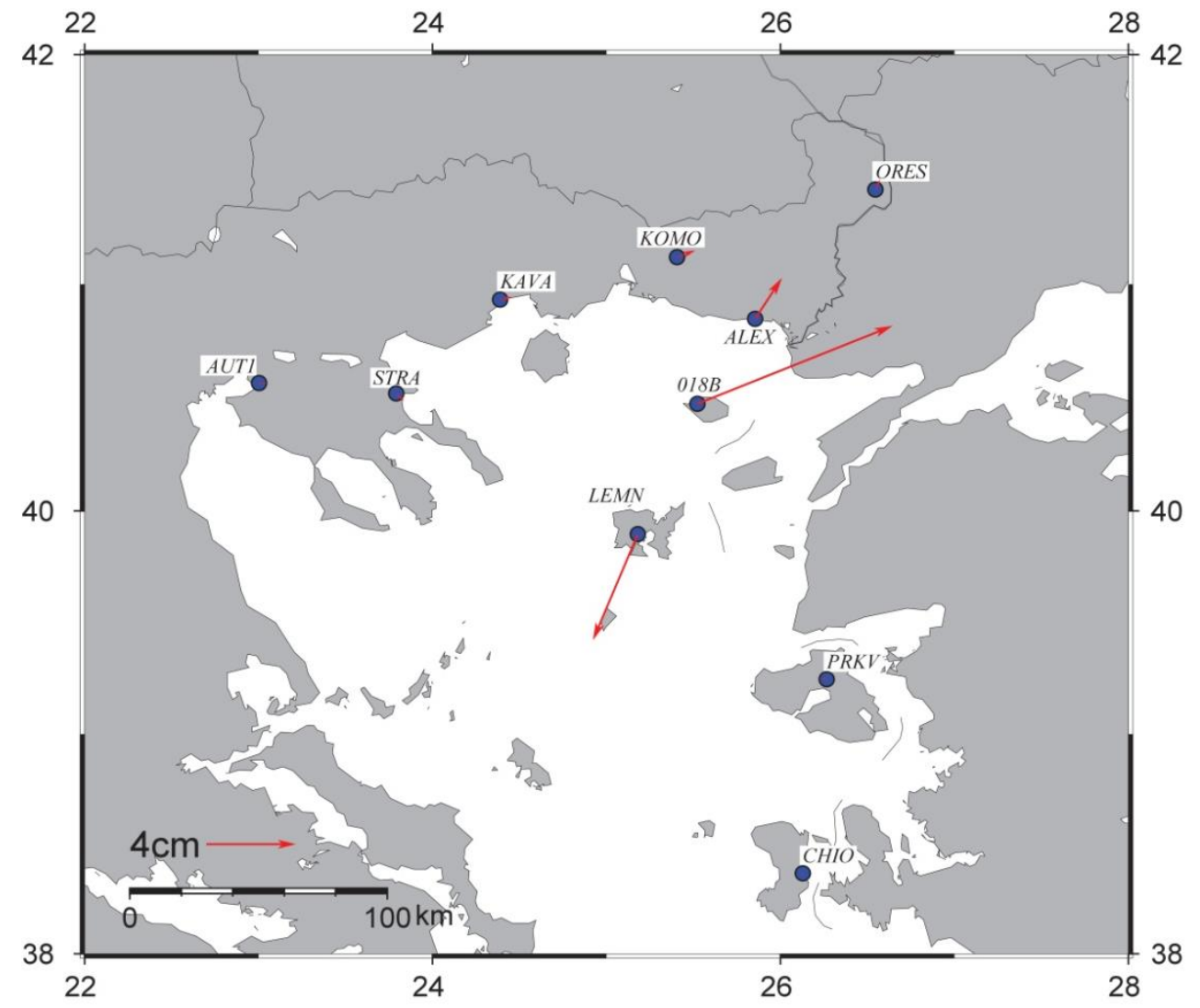

Figure 4 - Total horizontal seismic displacements in the area of North Aegean Sea for the period of May 20 to May 26, 2014. 
Table 1 - Total displacements for 13 GNSS stations due to the Samothrace Earthquake of May 24, 2014: ( $\delta N$, $\delta E$, $\delta U)$, 2-D and 3-D vectors.

\begin{tabular}{|c|c|c|c|c|c|c|c|c|c|}
\hline \multirow[t]{2}{*}{ Site } & \multirow[t]{2}{*}{ Location } & \multicolumn{2}{|c|}{$\begin{array}{l}\text { Approximate Position } \\
\text { (dec. deg) }\end{array}$} & \multicolumn{3}{|c|}{$\begin{array}{c}\text { Horizontal \& Vertical Displacement } \\
\left(\begin{array}{c}(\mathrm{mm}) \\
\text { (n) }\end{array}\right.\end{array}$} & \multicolumn{2}{|c|}{$\begin{array}{l}\text { Vector Norm } \\
(\mathbf{m m})\end{array}$} & \multirow[t]{2}{*}{$\begin{array}{r}\text { Azimuth } \\
\text { (dec. deg) }\end{array}$} \\
\hline & & Long. & Lat. & $\delta \mathbf{N}$ & $\delta \mathbf{E}$ & $\boldsymbol{\delta} \mathbf{U}$ & 2-D & 3-D & \\
\hline AUT1 & Thessaloniki, GR & 23.00 & 40.57 & -0.1 & 3.0 & -9.8 & 3.0 & 10.2 & 99.909 \\
\hline STRA & Chalkidiki, GR & 23.79 & 40.52 & -3.4 & 3.4 & 6.0 & 4.8 & 7.7 & 135.000 \\
\hline TUC2 & Chania, GR & 24.07 & 35.53 & 0.8 & 0.5 & 1.8 & 0.9 & 2.0 & 32.005 \\
\hline KAVA & Kavala, GR & 24.39 & 40.93 & 1.1 & 5.2 & -10.4 & 5.3 & 11.7 & 78.056 \\
\hline LEMN & Lemnos, GR & 25.18 & 39.90 & -47.8 & -20.1 & -6.6 & 51.8 & 52.3 & 202.807 \\
\hline KOMO & Komotini, GR & 25.41 & 41.12 & 3.1 & 8.2 & 8.9 & 8.8 & 12.5 & 69.291 \\
\hline 018B & Samothace, GR & 25.52 & 40.47 & 35 & 87.1 & 15.3 & 93.9 & 95.1 & 68.108 \\
\hline ALEX & Alexandroupolis, GR & 25.85 & 40.85 & 18.4 & 12.0 & -2.0 & 22.0 & 22.1 & 33.111 \\
\hline $\mathrm{CHIO}$ & Chios, GR & 26.13 & 38.37 & -0.9 & -0.3 & -3.2 & 0.9 & 3.3 & 198.435 \\
\hline PRKV & Lesvos, GR & 26.27 & 39.25 & 0.2 & -2.3 & 0.9 & 2.3 & 2.5 & 274.970 \\
\hline ORES & Orestiada, GR & 26.55 & 41.41 & 4.7 & 2.2 & 1.6 & 5.2 & 5.4 & 25.084 \\
\hline ISTA & Istanbul, TR & 29.02 & 41.10 & -1.6 & 0.7 & 0.7 & 1.8 & 1.9 & 156.371 \\
\hline TUBI & Gebze, TR & 29.45 & 40.79 & -0.6 & 0.6 & 0.0 & 0.8 & 0.8 & 135.000 \\
\hline
\end{tabular}




\section{Conclusions}

Displacement estimations have been estimated at the North Aegean Sea due to a strong earthquake occurred on May 24, 2014 between Samothrace and Limnos islands. Continuous GPS data from 21 permanent GNSS stations have been rigorously analysed and processed for a period of a week giving a daily time series position variation. The seismic effect caused some significant discontinuities on the 2-D position of the three nearest surrounding stations varying from 2.2 to $9.4 \mathrm{~cm}$ within a distance of about $70 \mathrm{~km}$ and being compatible in orientation with existed focal mechanisms. It is interesting to note that the deformation of the affected earth's crust evolved into two days, from May 23 to May 25. Position discontinuities from strong seismic events have to be taken into account for a realistic geodetic velocity field estimation, featured this way the permanent GNSS networks as valuable tools for accurate position and displacement estimation.

\section{Acknowledgments}

The Metrica S.A and National Cadastre and Mapping Agency S.A of Greece are acknowledged for providing GPS data used in this study. Figures were plotted using GMT (Wessel et al., 2013).

\section{References}

Altamimi, Z., Collilieux, X. and Métivier, L., 2011. ITRF2008: an improved solution of the international terrestrial reference frame, J. Geod., 85, 457-473, doi: 10.1007/s00190-011-0444-4.

Bitharis, S., Fotiou, A., Pikridas, C. and Rossikopoulos, D., 2015. A new crustal velocity field of Greece based on seven years (2008-2014) continuously operating GPS station data, In: IUGG 26th General Assembly, Prague, Czech Republic.

Boehm, J., Werl, B. and Schuh, H., 2006. Troposphere mapping functions for GPS and very long baseline interferometry from European Centre for Medium-Range Weather Forecasts operational analysis data, J. Geophys. Res. Solid Earth, 111, 1-9, doi: 10.1029/2005JB003629.

Dziewonski, A.M., Chou, T.A. and Woodhouse, J.H., 1981. Determination of earthquake source parameters from waveform data for studies of global and regional seismicity, J. Geophys. Res., 86, 2825, doi: 10.1029/JB086iB04p02825.

Fotiou, A. and Pikridas, C., 2012. GPS and Geodetic Applications, Second Edi., Ziti Publishing.

Ganas, A., Chousianitis, K., Drakatos, G., et al., 2011. NOANET : High-rate GPS Network for Seismology and Geodynamics In Greece.

Guidoboni, E. and Comastri, A., 2005. Catalogue of earthquakes and tsunamis in the Mediterranean area from the 11th to the 15th century, INGV-SGA, Bologna, $1037 \mathrm{pp}$.

Herring, T.A., King, R.W. and McClusky, S.C., 2010. Documentation of the GAMIT GPS Analysis Software release 10.4, Dep Earth Planet Sci Massachusetts Inst Technol Cambridge, Massachusetts, 1-171.

Papazachos, B. and Papazachou, C., 1997. The earthquakes of Greece, Second edition, Editions ZITI, Thessaloniki, 304 pp.

Papazachos, B. and Papazachou, C., 2003. Oi seismoi tis Elladhas (in Greek). Third edition, Editions ZITI, Thessaloniki, $286 \mathrm{pp}$.

Sboras, S., Chatzipetros, A., Pavlides, S., et al, 2015. The May 24, 2014 North Aegean Trough earthquake: stress change and displacement patterns, In: 6th International INQUA Meeting on Paleoseismology, Active Tectonics and Archaeoseismology, Miscellanea INGV. 356-360.

Sboras, S., Chatzipetros, A. and Pavlides, S., (submitted). Noerth Aegean active fault pattern and the May 24, 2014, Mw 6.9 earthquake, AGU Books, Wiley-Blackwell.

Tregoning, P., Burgette, R., McClusky, S.C., Lejeune, S., Watson, C.S. and McQueen, H., 2013. A decade of horizontal deformation from great earthquakes, Journal of Geophysical Research: Solid Earth, 118(5), 2371-2381, doi: 10.1002/jgrb.50154.

Wessel, P., Smith, W.H.F., Scharroo, R., et al, 2013. Generic Mapping Tools: Improved Version 
Released, Eos, Trans. Am. Geophys. Union, 94, 409-410, doi: 10.1002/2013EO450001. http://www.metricanet.gr/

http://www.hepos.gr/ 